\title{
Forging ahead with plans for sustainable growth
}

Eng Kiong $\underline{\text { Teo, }}$, мBвs

T

he year 2012 closed with a total of 1,331 new manuscripts submitted to the journal from 39 countries, with the majority of submissions from Singapore and Asia. Despite our expanding international reach, some $32 \%$ of manuscripts submitted (a 16\% increase from 2011) and $46 \%$ of the articles published last year were from local authors. Thus, we were able to strike a healthy balance of international and local content, retaining the distinctive local flavour of the Journal. The interest generated by some of our articles among the local media, especially those that directly impact the local population, attests to the Journal being uniquely Singaporean. Some of the articles that caught media attention in 2012 were topics pertaining to palliative care in children, tuberculosis control in Singapore and addictions such as gambling and binge drinking, with the most recent being a commentary by lawyers Eric Tin and Kang Yixian on specified minimum suspension term for doctors and other healthcare professionals - a topic that, in my opinion, will continue to interest medical practitioners in Singapore.

We also saw the attainment of our first impact factor of 0.73 ; though not a staggering figure, it does signal that we are heading in the right direction. A new CME series - Practice Integration \& Life-long Learning or PILL for short was launched in June last year. The PILL series, which aimed to integrate the latest medical evidence and deliver it in small, therapeutic doses, was well received by readers, who felt that the topics were not only relevant to their practice, but also easily digestible. We also introduced four theme-based issues in 2012, namely the Oncology, Infectious Disease, Psychological Medicine and Obstetrics \& Gynaecology issues. The journal front cover and layout underwent a revamp, receiving positive feedback from readers, who found the new look refreshing and more readable.

Overall, I think the Journal fared well in 2012, and we could not have achieved this without the hard work and support of our editors, reviewers and authors. In particular, I would like to appreciate Dr Andrew Peh, Adj Asst Prof Siau Chuin and A/Prof Ti Lian Kah, who finished their term of service on the Editorial Board, as well as all the 442 reviewers who completed their reviews in 2012. I am also immensely thankful for the authors who had chosen to submit their papers to the Journal last year. The annual SMJ Best Research Paper Award, presented to the top three research papers published each year, is our way of recognising authors for their excellent contributions to the Journal.

This year promises to be yet another exciting, albeit challenging year. Plagiarism and duplicate submissions continue to plague the Journal. These submissions not only stretch our already limited resources, but also slow down the review of articles that are more deserving. It is thus vital that we actively engage in efforts to prevent scholarly and professional plagiarism by implementing a more efficient system of comparing authored work against submitted content. Admittedly, the review process and waiting time for publication of accepted articles can also be further improved. In the backdrop of global economic uncertainties, rising costs and declining advertising revenue, we need to forge ahead with plans to grow the journal and yet maintain a sustainable model for open access publication. To these ends, we will be rolling out several new initiatives.

First, the Journal will start implementing a fixed article processing charge (APC) on online submissions from April 1, with provisions for waiver available for authors who are association members, as well as on a case-by-case basis. Since its inception in 1960, the SMJ has been freely accessible to the medical community, and has not levied any submission fees, or publication, excess page or colour charges on accepted papers. The APC, currently set at $S \$ 100$, is deliberately kept low so that it remains affordable for genuine contributors, and yet serves as a deterrent to low-quality, plagiarised or premature submissions. Furthermore, it ensures that both rejected and accepted authors contribute to the costs of administering peer review, and also allows for the processing charge to be set as low as possible due to the larger number. We will be releasing more details regarding the APC on our online manuscript submission and peer-review system at http://www.editorialmanager.com/singaporemedj/ in the coming months.

In addition to the APC, the Journal will be assigning a digital object identifier (DOI) to all articles published in 2013. This will not only enhance online article search, but also facilitate future electronic publication ahead of print, thereby reducing authors' waiting time from acceptance to print. Finally, we will be incorporating a powerful plagiarism screening tool into our online manuscript submission system in our efforts to curtail scholarly plagiarism and duplicate submissions.

For the Journal to continue publishing quality articles that add to the pool of medical knowledge, it is imperative that we have in place a viable economic model to support the administration of peer-review. Therefore, I earnestly urge our authors to continue to submit their manuscripts to us. With these new initiatives and your continued contribution and support, I am confident that the Journal will be poised for further growth in 2013. 